\begin{tabular}{|c|c|c|}
\hline (1) & $x 876$ & 1877. \\
\hline ug. $20 \ldots+10^{\circ} 1$ & July $29 \ldots+26 \cdot 1$ & Aus. 20 .. \\
\hline $23 \ldots-29^{\circ} 6$ & Aug. $21 \ldots+7 \cdot 2$ & $23 \cdots+18 \cdot 5$ \\
\hline t. $\begin{array}{r}9 \ldots-7{ }^{\circ} \\
12 \ldots-15.8\end{array}$ & Sept. 1o $\ldots+94$ & Sept. $12 \ldots+333$ \\
\hline $\begin{array}{rr}\prime \prime & 12 \ldots-158 \\
\text { Oct. } & 5 \ldots+7\end{array}$ & $\begin{array}{r}+219 \\
+\quad 3.8\end{array}$ & oct. $\quad 8 \ldots+54^{\circ}$ \\
\hline $28 \ldots+17 \cdot 2$ & I. & Dec. $10 \ldots+701$ \\
\hline & $\begin{array}{rr}\Rightarrow & 9 \ldots+12 \\
3 " & 26 \ldots+52^{\circ} \\
\text { Dec. } 11 \ldots+530^{\circ}\end{array}$ & $13 \ldots+$ \\
\hline
\end{tabular}

If yearly means of the above differences are taken we have :-

$$
\begin{array}{llllllr}
1875.76 & \ldots & \ldots & \ldots & \ldots & \ldots & -4.8 \\
1876.76 & \ldots & \ldots & \ldots & \ldots & \ldots & +19.4 \\
1877.73 & \ldots & \ldots & \ldots & \ldots & \ldots & +40.8
\end{array}
$$

These figures appear to indicate that a perturbation of the period is taking place, which of late has increased the differences between observation and calculation at the rate of about twenty-two minutes annually; the star is evidently one which deserves close attention at the hands of those observers who are following up the variables. With reference to previous observations of Algol and results derived from them, the reader will best consult Argelander in the seventh volume of the Bonn observations, and Schönfeld in V'ierteljahrsschrift der astronomischen Gesellsihaft, vi. p. 60.

THE REAPPEARANCE OF BRORSEN'S COMET.-It is notified that M. Tempel, director of the observatory at Arcetri, Florence, detected the short-period comet of Brorsen on January 14, in a position north following the nebula No. 4900 of Sir John Herschel's General Catalogue. The ephemeris by Dr. Schulze, of Döbeln, who has carried on the calculation of the perturbations from the last appearance of the comet in 1873 to the present year, does not commence until February 19 , so that it appears to have occurred to $\mathrm{M}$. Tempel that, with his advantages of climate and optical means, there was a possibility of an earlier observation of the comet, and he has taken steps to that effect accordingly. Dr. Schulze's elements for 1879 give for the place of the comet on January 14, at 6 h. M.T. at Florence, R.A. $23 \mathrm{~h}$. Iom. $38 \mathrm{~s}$., N.P.D. $118^{\circ} 57^{\prime}$, which is north-following the nebula named, so that there is no reason to doubt that the object observed, which is described as small, but brighter than the nebula (one of Sir W. Herschel's second class) is really Brorsen's comet. In this case, however, $M$. Tempel has succeeded in observing the comet, when, according to theory, it possessed a much less intensity of light than at any previous observation. At the time of his observation it would be distant from the sun 1.42 , and from the earth 1915 , whence the theoretical intensity of light, represented by $\frac{1}{r^{2} \triangle^{2}}$, is 0.135 ; the smallest value with which it had previously been observed corresponded to the last glimpse of the comet at Berlin on June 22 , I857, viz., $0^{\circ} 337$. Dr. Schuize's ephemeris will be found in No. 2220 of the Astronomische Nachrichten, commencing, as we have said, on February 19. On February 7 the comet's position at 6h. G.M.T. is in R.A. 23 h. $59^{\circ} 9 \mathrm{~m}$., N.P.D. $109^{\circ} 4^{\prime}$, and on February $\mathrm{r}$,

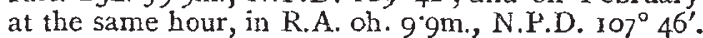

\section{SUN-SPOTS AND THE NILE}

$\mathrm{N}$ the 2 Ist instant $\mathrm{Mr}$. Francis $\mathrm{Cobb}$ read a paper on the financial and economical condition of Egypt, at the Society of Arts, in which he of course referred to the periodical rise of the Nile, and spoke of the desirability of discovering some system in the variations of this rise. Mr. Cobb, in considering this subject, bas been naturally drawn to an examination of the sun-spot period, and has attempted to discover if any relation exists between this period and the variations in the rise of the river. The period of Mr. Cobb's examination extends from 1866 to 1878 , and as might have been expected, he finds no relation whatever between any sun-spot maxima and minima, and the maxima and minima of the Nile floods. The years 1 866-67 were sun-spot minima; the rise of the Nile in these years was $28 \frac{1}{4}$ and $24 \frac{1}{2}$ feet respectively; 1872 was a maximum sun. spot year, and the rise of the Nile was $25^{\frac{1}{2}}$ feet; $1877 \mathrm{a}$. minimum sun-spot year, with 18 feet rise in the river; last year the rise was 30 feet. As some of the speakers in the discussion remarked, there is at present a desire to find relations between the stupendous cosmical phenomenon of sun-spots, and terrestrial occurrences, without considering local peculiarities. We do not know what might be the result if the records of Nile floods for a century were obtainable, and were compared with the various sun-spot: periods during that time; but we should say beforehand that in considering so literally narrow an occurrence as the rise of the Nile, many local considerations would have to be taken into account.

"It is impossible to say," Mr. Cobb went on, "that the rule, maximum spots, maximum rainfall, applies to Egypt. The cause of the irregularities of the Nile must clearly be looked for locally, the Blue Nile and Nyanza lakes having probably more to do with the matter than sun-spots. The telegraph, combined with a vigilant series of the operations of the Upper Nile, especially at the confluence of the Blue Nile, will prove more reliable for the protection of Egypt another year than any calcu. lations based upon solar physics."

We fear Mr. Cobb has but a vague idea of the applica. tion of solar physics to metecrology and other terrestria: phenomena. A perusal of the many letters which appea: in NATURE from our Indian meteorologists, will show that without a careful consideration of local and regional conditions no deduction drawn from sun-spot periods $p e$; se are of much value.

In the discussion which followed Dr. Mann endeavoured to draw the attention of the meeting to the science of the subject. While he apparently endorsed Mr. Cobb's opinion that the spots on the sun would not be found to have any dirt ct relation to the high and low Niles, he thought it would be perhaps as well to state exactly how this matter stood. The last development of the search after sun-spot influence Dr. Mann said, took the form of the discovery that the constantly recurring financial crises in this country were du: to the sun-spots; and he should like to point out what really was the influence of the sun upon the great physical changes going on in the world. There was no doubt that the presence of sun-spots had relation to the amount of force and energy issuing from the sun, and that when spots were abundant more solar energy was thrown out into space. When that was the case, the earth shared with all the other orbs in getting some increased force from the sun. There was no doubt either that movement of every kind on the earth was dependent on solas. action; and when increased energy was thrown out from the sun it told immediately on the water of the earth, and raised more of it into the sky in the form of vapour. But this did not mean that there would be an increased rainfall in one particular spot, but only that, being more vapour, there would be a greater rainfall over the whole earth. In a case like Egypt, the amount of rainfall was due to the presence or absence of an ocean wind blowing over the high grounds of Abyssinia. Therefore, though no doubt the sun-spots bad to do with the total rainfall, they had not necessarily anything to do with the local rainfall in one particular country like Egypt.

$\mathrm{D}^{\mathrm{r}}$. Mann explained that in these remarks he did not intend to imply that there was not a periodicity and regular order of some hind in social conditions and events which were connected with the requirements of finance, crisis, and things of that kind. He was quite satisfied that there was. But he thought there was too great an 
inclination to refer locally restricted events to large general causes.

Mr. Hyde Clarke, who was in the chair, drew attention to the fact that it was by a paper of his thirty years ago that public attention was first directed in what he might term a scientific form to this periodicity. Prof. Stanley Jevons, who was the great advocate for the application of the sun-spot theory to commercial crises, had reproduced the statements he made thirty years ago, and thus fresh attention had been called to them. For his part, he was no advocate for what was called the sun-spot theory, for he believed the sun-spots had no direct bearing on the periodicity of commercial crises, or upon the height of the Nile ; but as what Dr. Mann had said might appear to throw discredit on the periodicity of crises, he would briefly revert to the facts to which he had formerly called attention. He had then gone through the corn harvests, as shown by the prices in England for the last 400 years, for which data could be obtained, and his observations, which had since been repeated by Prof. Jevons, gave a series of facts over six centuries, showing that there was a periodicity in the crops, and consequently in the commercial phenomena dependent on them, of somewhere about ten years. Prof. Jevons had fastened on to that one fact, but had not referred to other observations he had made, which gave the clue to the question $\mathrm{Mr}$. Cobb had raised, whether it was possible to predict these periods. There was certainly, in a long period, a periodicity of about ten years, and if you laid out a diagram you would find this plainly shown, but yet in some places the lines of dearth or pienty would seem to come in the wrong place, and no one has yet been able to hit on the true law. He had stated that, as far as he could discover from the facts before him, there were, besides the periods of ten years, other periods of about twentysix years, and likewise a period of about ro4 years, and the opinion he formed was that these longer periods interfered with the shorter ones, and prevented any absolute calculation as to the future. At the same time the observation of these phenomena was not by any means an idle matter; there was this practical lesson to be drawn from it, that in periods of prosperity we must look forward to a period of adversity and prepare for it. Therefore the observation of Governments, and of the commercial community and financial institutions should be directed to these great phenomena of nature, which, after all, did govern the individual operations of man.

And this is all we contend for. That there is a connection between certain well-known cosmical phenomena, centring in the sun-spot period, is admitted by all whose researches give them a right to pronounce an opinion on the subject. What is the exact nature of this connection has yet to be discovered, though that we are on the road to it every careful reader of NATURE must admit. The immense social and economical results depending on the definite ascertainment of this connection make it the bounden duty and the interest of civilised Governments to do all in their power to further research in this direction, and we have no doubt that when the full truth is known it will be found that even the apparently capricious Nile is obedient to influences that may be regarded as ultimately cosmical.

\section{NOTES}

$\mathrm{WE}$ are pleased to see a suggestion in the Midland Counties Herald that in considering the arrangements for the restoration of the Reference Library, recently almost destroyed by fire, the authorities will not miss the opportunity they now have of supplying an omission in the public institutions of Birmingham, by organising a Natural History Museum, of equal value with the Reference Library which they are doing their best to restore. We heartily endorse this suggestion, and indeed it seems strange that so energetic and intelligent a town as Birmingham, with one of our most enterprising Natural History Societies in its midst, should not have had such an institution long ago. We are sure the matter only needs to be properly brought before the authorities and the citizens to have the blank speedily and properly filled up.

Mr. JoHn SADLER, so long assistant to Prof. Balfour, has been appointed to succeed the late Mr. McNab as curator of the Royal Botanic Gardens, Edinburgh.

IT is expected that Russian Turkestan will be very wëll represented at the anthropological exhibition which will be opened next summer at Moscow. We may already mention a very interesting collection of some dozens of skulls, found at Samarkand and belonging to a very remote epoch. A collection of dresses and implements of the inhabitants of the Zarafshan valley will be accompanied by a collection of ethnographic photographs; and among the inhabitants of this valley, the photographs and the skulls from the Galchi tribe will probably draw the special atten. tion of the scientific world. This tribe, which lives in the clefts of the Hinda-Kush at the sources of Zarafshan river, differs from all other Central Asian tribes, and is said to be the remnant of the army of Alexander the Great; indeed, its features are like those of the Greeks; but the tribe remains almost quite unexplored, because of their wildness and the insecurity of travel in those regions. Altogether, the Zarafshan district sends to the exhibition plenty of very valuable anthropological and ethnogra. phical materials.

THE unveiling of the Humboldt monument in Tower Grave Park, St. Louis, U.S., took place on December 24 last. The monument, as our readers will remeinber, is cast in bronze and executed after the design of the eminent German sculptor, Herr Ferdinand von Miller.

The Berlin Humboldt Academy, founded by the Scientific Central Union of that city, was inaugurated on January 13 last.

THE competitive examination held at the Paris Conservatoire des Arts et Métiers for the appointment of a Professor of Physics and Meteorology to the National School of Agriculture is said to have been very brilliant. It has ended by the appointment of M. Duclaux, Professor to the Faculty of Lyons, who was trained by M. Pasteur.

THE Times Paris Correspondent telegraphs on January 24 that the eruption of mud at the foot of Mount Etna was still going on, but with varying intensity. For two days after the earthquake of the $24^{\text {th }}$ ult. it was considerably stimulated, but it has since slackened, and the mud is more watery. An area of 7,000 square metres is already covered.

A CORRESPONDENT of the Colonies and India, writing from Wellington, New Zealand, on December 7 , says that a most important discovery of graphite has just been made in the back portion of the province. The Colonial laboratory has received specimens from boulders found in a creek, and these prove to be the purest and most compact samples yet discovered in the Colonies. The value of the discovery is enhanced by the fact that the existence of coal in immediate proximity is this indicated. In another spot, between Westport and Keefton, an extensive limestone cave has been discovered, and it is stated that it is traversed by a creek yielding good payable gold. The Geological Survey is being steadily pushed on, and Dr. Hector is now attempting to work his way to Waikato, in order to gather information as to the geology of that hitherto unexplored region.

MESSR5. LeChERTIER, BARBE, AND Co., of Regent Street, have sent us a wonderful shilling moist colour-box, which, in utility and the quality of the colours, surpasses snything we have seen. 